\title{
The Signature of Shallow Circulations, Not Cloud Radiative Effects, in the Spatial Distribution of Tropical Precipitation ${ }^{\mathscr{A}}$
}

\author{
Dagmar Fläschner, Thorsten MAuritsen, AND BJORn STEVens \\ Max Planck Institute for Meteorology, Hamburg, Germany \\ SANDRINE BONY \\ LMD/IPSL, CNRS, Sorbonne Universities, Paris, France
}

(Manuscript received 15 April 2018, in final form 8 August 2018)

\begin{abstract}
Recent research suggests cloud-radiation interaction as key for intermodel differences in tropical precipitation change with warming. This motivates the hypothesis that intermodel differences in the climatology of precipitation, and in its response to warming, should reduce in the absence of cloud-radiation interaction. The hypothesis is explored with the aquaplanet simulations by the Clouds On-Off Klimate Intercomparison Experiment performed by seven general circulation models, wherein atmospheric cloud radiative effects (ACREs) are active (ACRE-on) and inactive (ACRE-off). Contrary to expectation, models' climatology of tropical precipitation are more diverse in the ACRE-off experiments, as measured by the position of the intertropical convergence zone (ITCZ), the subtropical precipitation minima, and the associated organization of the tropical circulation. Also the direction of the latitudinal shift of the ITCZ differs more in simulations with inactive cloud radiative effects. Nevertheless, both in ACRE-on and ACRE-off, the same relationship between tropical precipitation and the mean vertical velocity (zonally, temporally, and vertically averaged) emerges in all models. An analysis framework based on the moist static energy budget and used in the moisture space is then developed to understand what controls the distribution of the mean vertical velocity. The results suggest that intermodel differences in tropical circulation and zonal-mean precipitation patterns are most strongly associated with intermodel differences in the representation of shallow circulations that connect dry and moist regions.
\end{abstract}

\section{Introduction}

General circulation models disagree concerning projected changes in regional precipitation with warming, especially in the tropics (Xie et al. 2015). The ability to consistently project regional precipitation change has not improved between phase 3 of the Coupled Model Intercomparison Project (CMIP3) and the subsequent model generation of phase 5 (Knutti and Sedláček 2013). This paper will explore possible reasons for the intermodel spread in tropical zonal-mean precipitation and its changes.

Supplemental information related to this paper is available at the Journals Online website: https://doi.org/10.1175/ JCLI-D-18-0230.s1.

Corresponding author: Bjorn Stevens, bjorn.stevens@mpimet. mpg.de
The intermodel spread in tropical precipitation change is known to be linked to uncertainty in how the tropical circulation-as measured by midtroposphere vertical velocity - changes with warming (e.g., Bony et al. 2013; Shepherd 2014; Xie et al. 2015). This, in turn, depends on the interaction between surface fluxes, atmospheric radiation, and moist convective processes. Whereas uncertainty in precipitation projections may also arise from uncertainties in projected forcing and from internal variability, the diversity of simulated precipitation changes with warming can largely be attributed to differences in how models are formulated and tuned (Hawkins and Sutton 2011). Even when the model configuration is simplified to an aquaplanet setup with fixed sea surface temperatures (SSTs) - thus removing, for example, intermodel differences in SST patterns, land-sea contrasts, atmosphere-vegetation interactions, and ocean circulations-differences in the response of tropical precipitation change to a uniform warming 
remain large (Stevens and Bony 2013). For these reasons, our analysis focuses on how different processes influence the tropical rainbands in idealized aquaplanet simulations. We do so in the belief that any general framework for understanding controls on tropical precipitation should first be able to explain precipitation differences across models in the somewhat simpler setting of the aquaplanet.

On a hemispherically symmetric aquaplanet, the position of the intertropical convergence zone (ITCZ), and whether it forms as a single feature along the equator or two rainbands distributed symmetrically around the equator, can depend on various factors. The ITCZ shifts from a single to a double structure as tropical SST gradients flatten (e.g., Dahms et al. 2011; Williamson et al. 2013; Oueslati and Bellon 2013b). Further factors influencing the ITCZ position on aquaplanets are the dynamical core and model resolution (Landu et al. 2014), the convection parameterization (Liu et al. 2010; Möbis and Stevens 2012; Oueslati and Bellon 2013a), the feedback between surface wind and evaporation (Numaguti 1993; Chou and Neelin 2004; Liu et al. 2010; Möbis and Stevens 2012), and solar constant specifications (Kirtman and Schneider 2000; Barsugli et al. 2005).

The important role of cloud radiative effects on the tropical circulation is also widely acknowledged (e.g., Ramanathan 1987; Slingo and Slingo 1988; Slingo and Slingo 1991; Randall et al. 1989; Sherwood et al. 1994; Bergman and Hendon 2000; Fermepin and Bony 2014; Li et al. 2015; Crueger and Stevens 2015). By modulating the spatiotemporal pattern of diabatic heating within the atmosphere, different cloud representations induce differences in the vertical profile of atmospheric radiative heating, something called the atmospheric cloud radiative effect (ACRE). Deep clouds found in the tropical convergence zones result in a net heating of the atmosphere, which concentrates in the mid- and upper troposphere. Low clouds found primarily in regions of relatively low SSTs induce a diabatic cooling, especially in the lower troposphere (Tian and Ramanathan 2002). Recently, the impact of ACREs on the ITCZ position in aquaplanets has also come into scientific focus. ACREs shift the ITCZ equatorward in six aquaplanet models (Harrop and Hartmann 2016). This result is confirmed by Popp and Silvers (2017), who additionally demonstrate that whereas the longwave ACRE is associated with an equatorward ITCZ shift, the shortwave ACRE induces a poleward shift. The longwave ACRE dominates such that in the net the ITCZ shifts equatorward.

Cloud radiative effects have long been known to be the root cause for intermodel spread in the surface temperature response to a doubling of the atmospheric $\mathrm{CO}_{2}$ concentration (e.g., Cess et al. 1990; Bony and Dufresne 2005;
Vial et al. 2013). A number of studies suggest that ACRE is also the root cause for intermodel spread in the precipitation and circulation response to surface warming (e.g., Voigt et al. 2014; Voigt and Shaw 2015; Oueslati et al. 2016). Focusing on the two models (MPI-ESM-LR and IPSL-CM5A-LR) with the most diverse changes in tropical precipitation with warming, Voigt and Shaw (2015) show that whereas the ITCZ response to warming is to contract in the MPI model-such that precipitation increases strongly at the equator and decreases in the remaining tropics - the IPSL model weakly enhances precipitation in the entirety of the tropics. Using the cloudlocking technique (e.g., Wetherald and Manabe 1988; Mauritsen et al. 2013) to attribute the circulation response with warming to various constituent changes, they conclude that the circulation response to warming - and with that the precipitation response-is most strongly shaped by how the cloud radiative heating changes with warming.

The relevance of ACREs on the intermodel spread in precipitation changes with warming leads us to hypothesize the following: if ACREs are the key to intermodel differences with warming, then the models should agree more in their response to warming if the interaction between clouds and radiation is inhibited. This line of reasoning leads one to hypothesize that different responses to ACRE may also explain intermodel spread in the control climate. We explore these ideas by analyzing model simulations from the Clouds On-Off Klimate Intercomparison Experiment (COOKIE; Stevens et al. 2012), which provides simulations by seven models where the cloud-radiation interaction is inhibited, and simulations where ACREs are active. Like Voigt and Shaw (2015), and for reasons stated above (see also Medeiros et al. 2015), we focus on the aquaplanet configuration. Even in the absence of cloud-radiation interaction, we find surprisingly large, and in some cases larger, differences both in how precipitation changes with warming and how it is distributed in the control climate.

On the basis of these findings, subsequent analysis is devoted to interpreting the origin of differences in the spatial distribution of precipitation in the control climate. We demonstrate that spatial differences in precipitation are strongly associated with differences in the circulation-as measured by vertically averaged largescale vertical velocity. This motivates our use of the vertically integrated moist static energy budget framework (Neelin and Held 1987) to link differences in the largescale vertical motion field to differences in atmospheric stability and/or heating. We show that, from this point of view, differences in the stability across models have little influence on circulation, and hence precipitation, differences. Though differences in the heating appear to explain differences in circulation across the models, 
these differences are not associated with processes that usually come to mind, such as radiation or surface fluxes. Rather it appears necessary to account for differences in the structure of the circulation itself, rather than just its magnitude, to explain differences in precipitation across the models.

The outline of the remainder of the manuscript is as follows. After describing the COOKIE simulations in more detail (section 2), we compare the intermodel spread in different precipitation and circulation characteristics of the tropics between simulations with active and inactive cloud-radiation interaction (section 3 ). The moist static energy framework is developed and employed to the COOKIE aquaplanet simulations in section 4. Further, we take a closer look at the shallow circulation in moisture space (section 6). Findings are summarized in section 7 .

\section{Data}

COOKIE consists of two main sets of experiments: 1) the "ACRE-on" simulations where clouds interact with the radiation as normal and 2) the "ACRE-off", simulations where clouds are artificially made transparent to radiation by setting their cloud liquid and cloud ice to zero in the calculation of radiative transfer. Note that clouds can still develop in the ACRE-off experiment-they just do not influence radiation. Besides the different radiative settings, the two sets of experiments are identical. The comparison between both sets of experiments allows assessing how the atmospheric cloud radiative effect impacts the mean state of the models, for example, their precipitation patterns and circulation.

As part of COOKIE, both standard AMIP and aquaplanet simulations have been performed. We limit our analysis to the idealized aquaplanet model configuration. In this configuration, the planet's surface is assumed to be saturated with a sea surface temperature that is prescribed as a function of latitude $\varphi$ only according to "Qobs" in Neale and Hoskins (2000). The latitudinal dependence is called Qobs because it most closely matches the mean latitudinal variation of the climatological SSTs. Following Qobs, the surface temperatures peak at $27^{\circ} \mathrm{C}$ at the equator, decline throughout the tropics and midlatitudes, and are held constant poleward of $60^{\circ}$ latitude at $0^{\circ} \mathrm{C}$. Besides the modifications to the calculation of radiative transfer in ACRE-off, the COOKIE aquaplanet configuration follows that of the aquaplanets in CMIP5. The solar radiation is specified as perpetual equinox conditions, by removing the seasonal cycle, but the diurnal cycle is retained. Sea ice, orography, and aerosols are set to zero.
TABLE 1. Aquaplanet COOKIE models used in this study.

\begin{tabular}{|c|c|c|}
\hline Model & Grid points & Reference \\
\hline CNRM-CM5 & $256 \times 128$ & Voldoire et al. (2013) \\
\hline MPI-CM5-LR ${ }^{a}$ & $192 \times 96$ & Stevens et al. (2013) \\
\hline MIROC5 & $256 \times 128$ & Watanabe et al. (2010) \\
\hline IPSL-CM5A-LR & $96 \times 96$ & Dufresne et al. (2013) \\
\hline IPSL-CM5B-LR ${ }^{\mathrm{b}}$ & $96 \times 96$ & Hourdin et al. (2013) \\
\hline HadGEM2-A & $192 \times 144$ & Collins et al. (2011) \\
\hline MRI-CGCM3 & $320 \times 160$ & Yukimoto et al. (2012) \\
\hline
\end{tabular}

a Although the COOKIE version of the MPI model is essentially similar to the MPI-ESM-LR used in CMIP5, we refer to it with the name it was given in the COOKIE project.

${ }^{\mathrm{b}}$ The $4 \mathrm{~K}$ ACRE-on experiment is not provided.

We analyze aquaplanet simulations with the control Qobs SST as the lower boundary condition and simulations where SSTs are uniformly raised by $4 \mathrm{~K}$ (referred to as $4 \mathrm{~K}$ ). Thus two states and two different specifications of clouds, which comprise a total of four experimental configurations, are available for the investigation of intermodel spread in precipitation patterns and their changes with warming. Six modeling centers performed the COOKIE simulations (Table 1), where one center performed simulations with two different physics packages (IPSL-CM5A-LR and IPSL-CM5B-LR). All modeling centers were using the model version corresponding to what they used in CMIP5 for the simulations, except for the MPI model. A slightly newer version than in CMIP5 was used (ECHAM6.1.05) with added bug fixes that do not influence the mean climate to any significant extent.

Though the surface temperatures should be identical to the Qobs profile in all models according to the COOKIE protocol, this is not the case. The MRICGCM3 model has higher peak SSTs than the remaining models, because a skin sea surface temperature scheme is employed and the Qobs profile is only used to fix the subskin layer temperature. This leads to steeper SST gradients especially near the equator, which complicates the direct comparison to the other models. Additionally, the MIROC5 model uses the Qobs profile in both ACRE-off simulations but a different SST profile in the ACRE-on simulations (see Fig. S1 in the online supplementary material) with steeper SST gradients close to the equator [named "Control" profile in Neale and Hoskins (2000)]. Models tend to place the ITCZ more equatorward when the SST gradients are steeper (Williamson et al. 2013). In MIROC5, the impact of atmospheric cloud radiative effects on climate variables is more difficult to interpret because differences between ACRE-on and ACRE-off simulations might also arise from differing SST profiles. We focus our analysis on the tropics, which are defined as areas 
equatorward of $\pm 30^{\circ}$ latitude. Because the aquaplanet is a hemispherically symmetric configuration, variables are averaged over both hemispheres for zonal-mean quantities so as to minimize statistical asymmetries that arise from a too-short simulation duration.

Analysis is performed on monthly averaged fields, which are then further averaged in time to study the climatological behavior of the simulations. To facilitate a comparison of the modeled precipitation fields, and their changes, we fit a cubic spline to the hemispherically and zonally averaged precipitation fields. Comparisons of different precipitation features are then performed in the space of these piecewise analytic functions. This approach was chosen to help minimize the impact of different discretizations of the meridional dimension.

\section{ACRE impact on intermodel spread in tropical precipitation and circulation}

The zonal-mean precipitation in the tropics is characterized by strong precipitation bands associated with the ITCZ and subtropical precipitation minima (Fig. 1). In both ACRE-on and ACRE-off experiments, a double ITCZ emerges in most models, where the precipitation maximizes in two peaks symmetrically about the equator. Only two models show a single ITCZ, where the peak precipitation is centered at or very near the equator, in ACRE-on. It is not immediately obvious whether models agree more in ACRE-on or ACRE-off in their zonalmean precipitation.

We investigate the intermodel spread in the precipitation climatology and its change with warming using the precipitation indicators defined by Popp and Lutsko (2017). These are evaluated using the cubicspline fit to the zonally and temporally averaged precipitation fields of each model as discussed in section 2 . Because of the hemispheric symmetry of these simulations, the number of indicators describing the zonalmean precipitation reduces, from the originally defined nine, to only five (Fig. 1c). Three of the indicators have the unit of precipitation: the precipitation magnitude at the equator $P_{E}$, the difference between peak precipitation and $P_{E}$, denoted as $P_{D}$, and the difference between peak precipitation and subtropical minimum precipitation $P_{H}$. The two remaining indicators describe the placement of the precipitation extrema in terms of latitude $\varphi$ : the latitude where the ITCZ is located $\varphi_{I}$ and the latitude of subtropical minimum precipitation $\varphi_{M}$. Note that we introduce $\varphi_{M}$ here, which on aquaplanets relates to the corresponding indicator $\varphi_{W}$ defined by Popp and Lutsko (2017), as $\varphi_{M}=\varphi_{W} / 2$.

On the whole, ACRE tends to increase the amount of precipitation falling on the equator in all models. This is

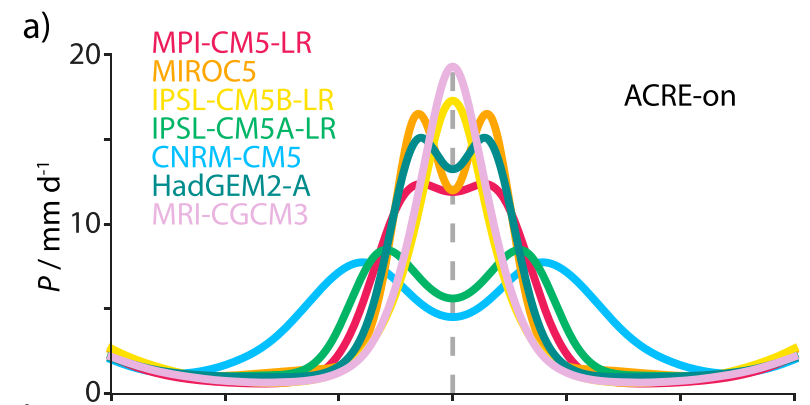

b)

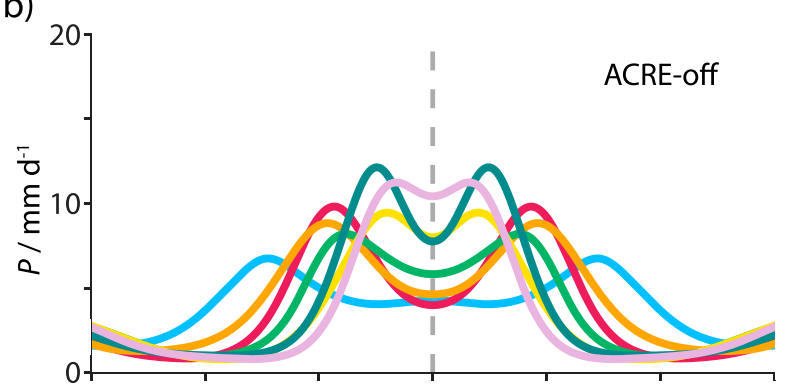

c)

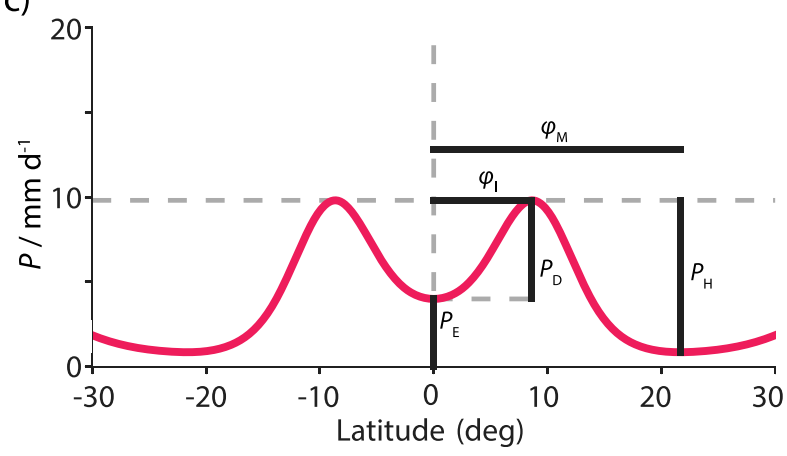

FIG. 1. Zonal-mean precipitation as a function of latitude of (a) the control ACRE-on and (b) the control ACRE-off experiment. (c) The five precipitation indicators needed to characterize zonal-mean precipitation in the tropics of an aquaplanet, following Popp and Lutsko (2017). To reduce the dependence on the model's horizontal resolution in estimating extrema, we fit a cubic spline to the zonal-mean precipitation here and use these fitted functions in all following analysis of zonal-mean quantities.

evident in the tendency of points to lie below the diagonal in Fig. 2a but also is consistent with the placement of all the other indicators relative to the diagonal. ACRE causes a robust drying of the subtropics, fewer differences between precipitation on the equator and its peak value near the equator, as well as a shift of the offequatorial precipitation peaks toward the equator. These findings are consistent with earlier analysis by Harrop and Hartmann (2016) and Popp and Silvers (2017). Here we show that this result generalizes also to the warmer (4K) climate.

The COOKIE models suggest that for a given model, the effect of ACREs on the distribution of precipitation 
a)

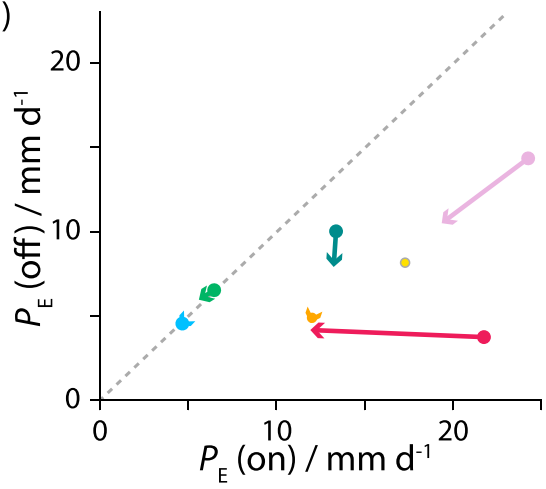

d)

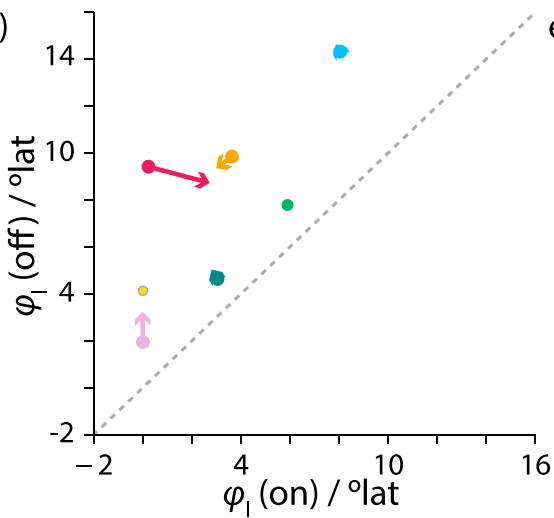

b)
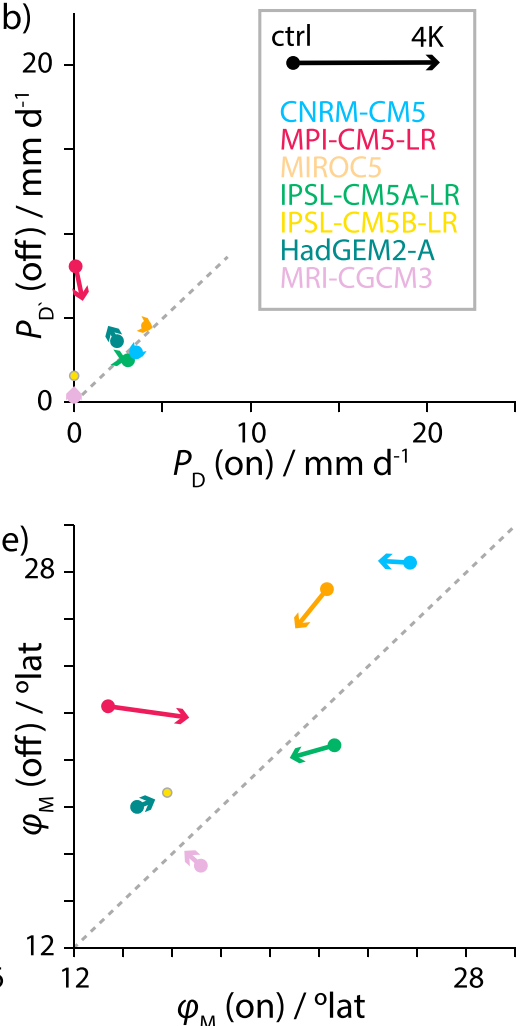
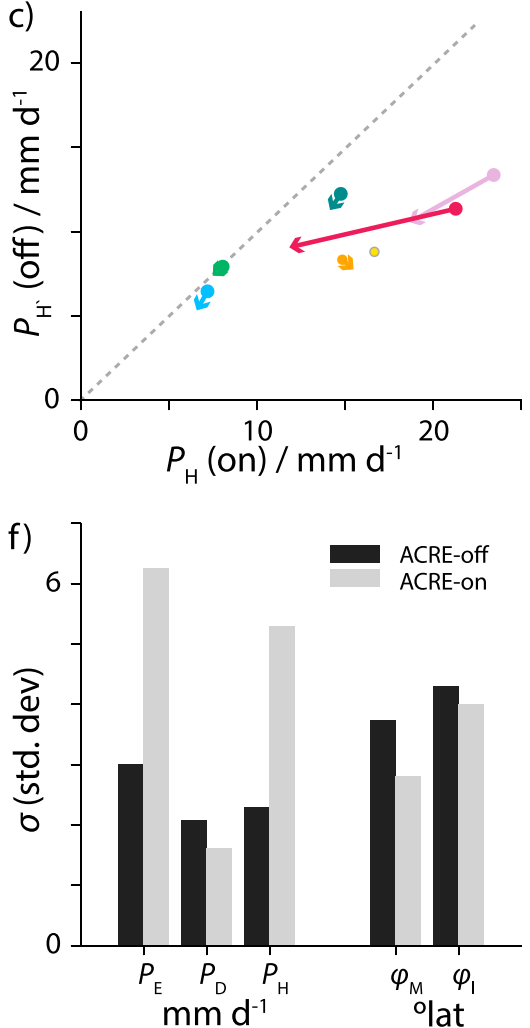

FIG. 2. (a)-(e) Comparison of the five indicators defined in Fig. 1c between ACRE-on and ACRE-off for both the control and the 4K experiments. In (a)-(e), points below the diagonal are indicative of the particular quantity being smaller in the presence of ACRE; likewise changes with warming that are less inclined than the diagonal are indicative of larger changes with warming in the presence of ACRE. (f) The intermodel standard deviation (taken across control and $4 \mathrm{~K}$ experiments for either ACRE-on or off) for the five indicators. Note that the IPSL-CM5B-LR 4K ACRE-on experiment is missing.

is robust. There is little indication, however, that ACREs are responsible for intermodel differences in either the spatial distribution of precipitation or in its change with warming. Both findings are contrary to our expectation. In terms of intermodel spread, as compared to ACREon, ACRE-off models are more similar in two magnitude indicators $\left(P_{E}\right.$ and $\left.P_{H}\right)$, but less similar in the location indicators and in $P_{D}$. This is true both in terms of absolute model spread (Figs. 2a-e) and the standard deviation of this spread (Fig. 2f). Note that $P_{H}$ and $P_{E}$ are highly correlated (with a coefficient of determination $R^{2}=0.91$ ), such that the spread in both quantities may be connected. The greater disagreement in ACRE-off among models in at least three of the five indicators is surprising and appears to refute the hypothesis that models should behave more similarly in the absence of cloud-radiation interaction.

With the help of the COOKIE experiments, we investigate how the intermodel spread in the ITCZ shift with warming is impacted by cloud-radiation interactions (Fig. 3). This analysis is motivated by the finding of Voigt and Shaw (2015). They analyzed the MPI-CM5-LR (similar to the MPI-ESM-LR, see Table 1) and IPSLCM5A-LR models in the ACRE-on experiment and used the cloud-locking technique to demonstrate that different cloud radiative responses to warming are key for the deviating ITCZ shifts in these two models. Based on their analysis, ACRE is responsible for a strong equatorward

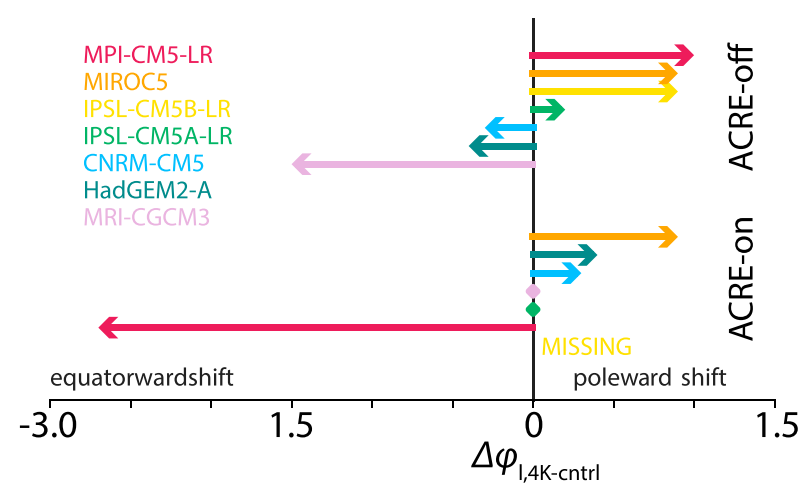

FIG. 3. ITCZ shift because of raising SSTs uniformly by $4 \mathrm{~K}$ compared between ACRE-off and ACRE-on. Note that the IPSLCM5B-LR 4K ACRE-on experiment is missing. 


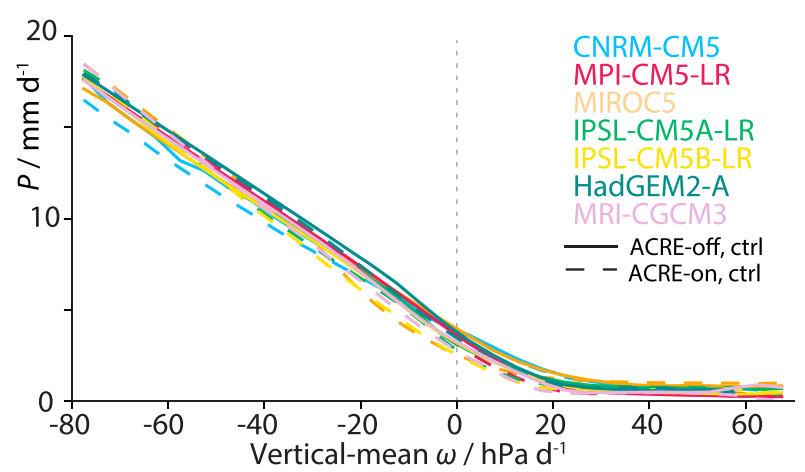

FIG. 4. Relationship of tropical precipitation with the verticalmean vertical (in pressure coordinates) velocity $\bar{\omega}^{v}$. The precipitation is averaged in bins of $\bar{\omega}^{v}$ of $5 \mathrm{hPa}$ day ${ }^{-1}$. Negative $\bar{\omega}^{v}$ values denote convective regimes, and positive $\bar{\omega}^{v}$ values denote subsidence regimes.

shift in the MPI model by $2.7^{\circ}$ but no shift in the IPSL model, and thus is responsible for a large part of the differences between these two models' response to warming. Their finding is reproduced by our analysis of the COOKIE experiments for these two models. However, this finding does not hold when the analysis is extended to more models. Differences in other models, for instance, compare HadGEM2-A and IPSL-CM5A-LR (Fig. 3), become larger in the ACRE-off experiments.

Even the tendency of ACRE to induce equatorward shifts in the ITCZ with warming (relative to ACRE-off simulations), which at least is consistent in the IPSLCM5A-LR and MPI-CM5-LR simulations, is not robust across the model ensemble analyzed here. In the HadGEM2-A and MRI-CGCM3 simulations, the ITCZ shifts poleward when ACRE is included. In the MIROC5 simulations, the ITCZ response to warming seems to be independent of whether cloud-radiation interaction is active or inactive, though this might be influenced by the different SST profiles in ACRE-on and ACRE-off. Hence, the effect of ACRE appears independent of already large differences in ITCZ shifts in the ACRE-off simulations; in some cases, it exacerbates differences in precipitation shifts between models, in other cases, its effect reduces the spread between models.

The above analysis suggests that neither changes in precipitation with warming nor differences in precipitation itself can be explained by cloud radiative interactions. We thus explore sources of differences in precipitation across models by noting that precipitation is strongly coupled to circulation, which then presents a framework for exploring factors influencing the circulation. The close and robust relationship between precipitation and circulation is illustrated by plotting the mean precipitation against the mean circulation, as is done in Fig. 4. Here the circulation is measured by the

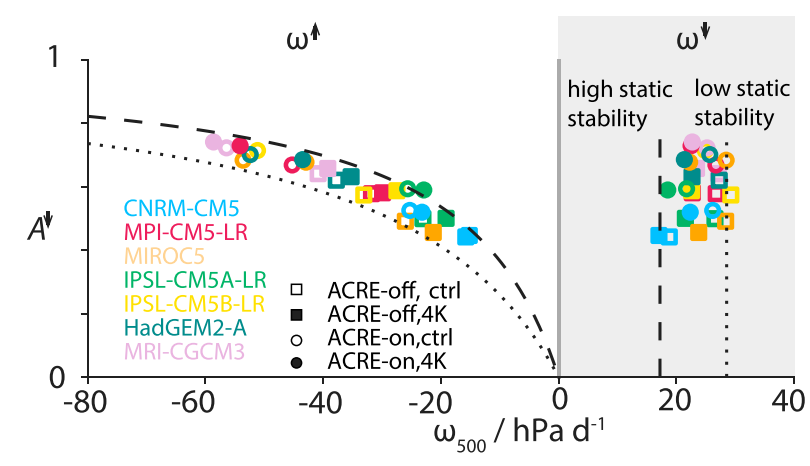

FIG. 5. The relationship of tropical-mean upward and subsidence pressure velocity at $500 \mathrm{hPa}(\omega \uparrow$ and $\omega \downarrow$, respectively) with the subsidence area fraction $A \downarrow$ in the COOKIE aquaplanet simulations. The vertical gray line marks the border between the convective (negative $\omega_{500}$ ) and subsidence regime (positive $\omega_{500}$ ). The vertical velocities according to a mean subsidence velocity estimated with a low static stability of $0.035 \mathrm{~K} \mathrm{hPa}^{-1}$ and a high static stability of $0.058 \mathrm{~K} \mathrm{hPa}^{-1}$ are marked by the dotted and dashed lines, respectively, when assuming a radiative cooling rate of $1 \mathrm{~K} \mathrm{day}^{-1}$; the subsidence area fraction for the high and low static stability cases is then given by $A \downarrow=-\omega \uparrow /(\omega \downarrow-\omega \uparrow)$.

mean mass flux in the midtroposphere, as the operator $\left(\digamma^{v}\right)$ denotes a mass-weighted vertical mean. Strong upward mass fluxes (negative $\bar{\omega}^{v}$ ) are associated with strong precipitation, whereas precipitation amounts are independent of the subsidence velocity for $\bar{\omega}^{v}$ approximately greater than $15 \mathrm{hPa} \mathrm{day}^{-1}$. This relationship is independent of whether ACREs are active or inactive.

The close relationship between precipitation and vertically averaged vertical velocity implies that differences in the zonal-mean precipitation characteristics translate into differences in the organization of the circulation in the tropics. Specifically, the ITCZ position is a good indicator for the fractions of upward- and downward-moving air masses. Following a simple consideration of mass conservation (e.g., Bjerknes 1938), the fraction of area with subsiding air masses $A \downarrow$, a measure also used for the characterization of convective aggregation (e.g., Coppin and Bony 2015; Becker et al. 2017), is also given by the relationship

$$
A \downarrow=-\frac{\omega \uparrow}{\omega \downarrow-\omega \uparrow},
$$

with $\omega \uparrow$ denoting the tropical-mean upward and $\omega \downarrow$ the tropical-mean downward vertical velocity. Figure 5 shows the relation of the subsidence area fraction with $\omega \uparrow$ and $\omega \downarrow$ estimated at $500 \mathrm{hPa}$, where the vertical motion strength at $500 \mathrm{hPa}$ is a widely used proxy for the largescale tropical circulation (Bony et al. 2004). As expected, $A \downarrow$ is fairly unrelated to the strength of mean subsiding motion at $500 \mathrm{hPa}\left(R^{2}=0.06\right)$, because subsiding motion is controlled by the ratio of radiative cooling and 

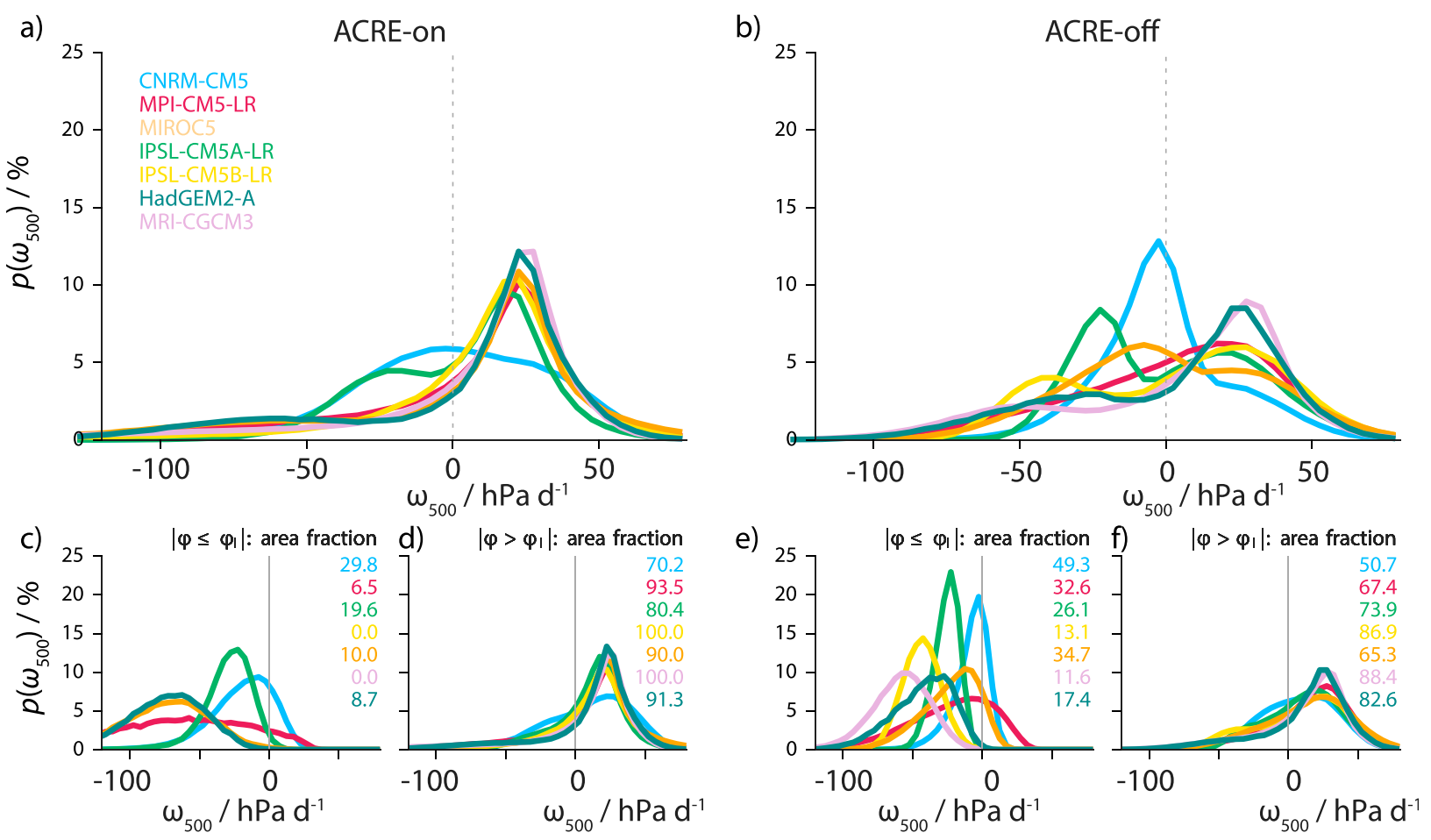

FIG. 6. Probability density function of the vertical pressure velocity at $500 \mathrm{hPa}\left(\mathrm{PDF}_{\omega_{500}}\right)$ in the control (left) ACRE-on and (right) ACRE-off experiment. (a),(b) The total tropical $\mathrm{PDF}_{\omega_{500}}$ is separated into the PDF $\operatorname{\omega os}_{500}$ considering only tropical areas (d),(f) poleward of the ITCZ latitude and (c),(e) equatorward of the ITCZ latitude. The respective fractions of tropical areas are given (\%). The data are binned by $5 \mathrm{hPa}$ day $^{-1}$.

the static stability in clear-sky regions-note that under warming, the stability is, as expected, higher and the $\omega \downarrow$ smaller. Therefore, $\omega \uparrow$ has to vary according to mass conservation arguments, which yields stronger convective motion for larger $A \downarrow$. In the models, $\omega \uparrow$ aligns well within the bounds of low and high static stability, which here serve as an estimate of the minimum and maximum $\omega \downarrow$ for an assumed typical tropical clear-sky cooling rate of $1 \mathrm{~K} \mathrm{day}^{-1}$ (e.g., Hartmann and Larson 2002). Convective motion is generally weaker in ACRE-off because the more poleward ITCZ positions imply smaller subsidence area fractions, thus fewer nonconvecting areas. Indications of the intermodel spread found in the ITCZ position extend to the intermodel spread in subsidence area fraction because both are anticorrelated $\left(R^{2}=0.88\right)$. Figure 5 shows how, through mass conservation, small differences in the subsidence area fraction, and thus the convective aggregation, account for large differences in the convective motion and thereby the strength of the tropical overturning circulation.

We further explore the organization of the tropical circulation in more detail via the probability density function of the vertical pressure velocity at $500 \mathrm{hPa}\left(\mathrm{PDF}_{\omega_{500}}\right)$. In the ACRE-on experiment, with the exception of
CNRM-CM5, the models agree well on the negatively skewed shape of $\mathrm{PDF}_{\omega_{500}}$ (Fig. 6a), with the typical peak at subsidence velocities between 15 and $30 \mathrm{hPaday}^{-1}$ controlled by clear-sky radiative cooling and the static stability (e.g., Bony et al. 2004). However, when simplifying the model configuration by removing cloud-radiation interaction, the statistics of the circulation differ more markedly among models (Fig. 6b). The absence of atmospheric cloud radiative effects thus increases the intermodel spread in the statistics of the large-scale circulation in the tropics. As cloud-radiation interaction tends to dampen differences among models, the differences in how models couple convection to circulation are likely larger than one would suppose by looking at simulations with active cloud radiative effects.

A look at $\mathrm{PDF}_{\omega_{500}}$ separately diagnosed only for areas poleward of the ITCZ position (Figs. 6d,f) and areas between the two ITCZs (Figs. 6c,e) gives some indication that the differences in the tropical $\mathrm{PDF}_{\omega_{500}}$ stem from areas equatorward of the ITCZ-the inner-ITCZ zone. The PDFs in the nonconvecting areas, which are expected in regions poleward of the ITCZ, show similar shapes among models as well as the ACRE-on and ACRE-off experiments. Interexperiment differences between on/off simulations thus are rooted in the 
inner-ITCZ zone. In the inner-ITCZ zone, which is characterized by upward motion, the peaks of $\mathrm{PDF}_{\omega_{500}}$ are located at negative vertical pressure velocities, though of different magnitudes among the models. The strength of the convective motion is similar between on/off simulations in IPSL-CM5A-LR and CNRM-CM5; weakens in the absence of clouds for HadGEM2-A, MPICM5-LR, and MIROC5; and cannot be compared in MRI-CGCM3 and IPSL-CM5B-LR as both have a single ITCZ in ACRE-on. For MIROC5, it is unclear whether the shift in mean convective velocity is merely due to cloud radiative effects or also due to a different SST profile. Because the area fraction of the inner-ITCZ zone is greater in ACRE-off, the model inconsistencies imprint more strongly on the total tropical $\omega_{500}$, leading to larger intermodel spread in the absence of clouds.

Contrary to the hypothesis that models should agree more in the absence of cloud-radiation interaction, we found greater differences in the characteristics of tropical precipitation, circulation, and in precipitation pattern changes with warming in ACRE-off than in ACRE-on. Cloud-radiation interaction is not the root of intermodel differences in this ensemble. Differences among models are evident in both precipitation and circulation statistics, with the largest differences in the innerITCZ region in the latter. The circulation as measured by the vertical-mean vertical velocity is an excellent predictor of precipitation across models and experiments.

\section{Prediction of vertical velocity by deep-mode moist static energy framework}

In this section, we develop a simple theoretical framework to understand the tropical precipitation distribution. The framework is inspired by the approach in Bony et al. (2013) but has also been used in a number of other studies (e.g., Bretherton and Sobel 2002; Chou and Neelin 2004; Byrne and Schneider 2016). We focus on the ACRE-off models, because explaining the diversity of precipitation features in this set of simulations would appear to be a prerequisite to understanding differences in more complex settings. The moist static energy framework relates fluxes of energy into the column to the strength of the overturning circulation, as measured by the vertical-mean vertical velocity (in pressure coordinates), which in turn informs about precipitation, given the close relationship in Fig. 4. We derive the framework from the column-integrated moist static energy budget in stationarity,

$$
0=F_{\text {sen }}+F_{\text {lat }}+R-\langle\mathbf{v} \cdot \nabla h\rangle-\left\langle\omega \frac{\partial h}{\partial p}\right\rangle
$$

where $F_{\text {sen }}$ and $F_{\text {lat }}$ denote the sensible and moisture contribution to the surface enthalpy flux, $R$ the column radiative fluxes in the atmosphere, $\mathbf{v}$ the horizontal velocity, $\omega$ the vertical velocity (in pressure coordinates), $\langle\cdot\rangle$ the mass-weighted vertical integral, and $h$ the moist static energy. The moist static energy $h=c_{p} T+g z+\ell_{v} q$, with the isobaric specific heat of dry air $c_{p}$, the absolute temperature $T$, the specific humidity $q$, enthalpy of vaporization $\ell_{v}$, and the geopotential $g z$, is a convenient measure of the energy content of a static air parcel as it is conserved for adiabatic parcel displacements in a barotropic atmosphere. A typical tropical $h$ profile has large values at the surface associated with high specific humidity and temperature. With increasing height, the humidity content decreases rapidly, leading to a midtropospheric minimum in $h$. In the upper troposphere, where $\ell_{v} q$ is low, $h$ increases again as it increasingly takes on the structure of the dry static stability, $c_{p} T+g z$. The two right-hand side terms of Eq. (2) are the horizontal and vertical advection of $h$, respectively.

To the extent that $\omega$ can be approximated by a deep vertical mode, Eq. (2) can be reformulated to relate the amplitude of this mode to the other energy sources, that is, surface turbulent fluxes, radiation, and advection. There is some justification for the assumption of a single deep vertical mode as such a structure explains most of the variance in $\omega(p)$ in the reanalyses of meteorological data (Trenberth et al. 2000; Yuan and Hartmann 2008). This assumption is also frequently used in simplified models of the tropical atmosphere (e.g., Neelin and Held 1987; Neelin and Zeng 2000; Zeng et al. 2000). Hence, here we ask to what extent such an assumption can be used to help interpret sources of intermodel differences through Eq. (2).

The deep-mode vertical velocity at each grid point then is represented by the product of the assumed deepmode structure $\phi_{d}(p)$ and a corresponding amplitude given by the mass-weighted vertical-mean pressure vertical velocity $\bar{\omega}^{v}$, such that

$$
\omega(p)=\bar{\omega}^{v} \phi_{d}(p)+\omega_{s}(p)
$$

where $\omega_{s}(p)$ is the residual vertical velocity due to other (generally shallower) modes. Although formally it is a residual, for simplicity $\omega_{s}(p)$ is often referred to as shallow-mode vertical velocity, hence the subscript " $s$." The decomposition in Eq. (3) allows us to write the vertical advection term in Eq. (2) as the sum of deepmode and shallow-mode vertical advection $\left(V_{h}^{s}\right)$,

$$
-\left\langle\omega(p) \frac{\partial h}{\partial p}\right\rangle=\bar{\omega}^{v} \Gamma_{d}-V_{h}^{s}
$$


with $\Gamma_{d}=-\left\langle\phi_{d}(p) \partial h / \partial p\right\rangle$ defining the "gross moist stability," which we subscript by " $d$ " as a reminder of its association with a deep vertical mode.

The gross moist stability can be understood as a normalized vertical advection representing the efficiency of exporting energy from the atmospheric column. Originally, the gross moist stability has been introduced by Neelin and Held (1987, p. 4) as a "convenient way of summarizing our ignorance of the details of the convective and large-scale transient." Since then, many different definitions for the gross moist stability have been used (for a review, see Raymond et al. 2009). Depending on the definition, gross moist stability values are positive in the entirety of the tropics (Yu et al. 1998; Chou et al. 2013) or become negative in tropical areas where shallow convection predominates (e.g., Back and Bretherton 2006; Bui et al. 2016) or in the early stages of the convective life cycle characterized by shallow convection (e.g., Inoue and Back 2015a,b). Shallow convection is characterized by low-level convergence and midlevel divergence. Because of the vertical profile of $h$, with high surface values, a midtropospheric minimum, and upper-tropospheric increases, the flow associated with shallow convection leads to a net import of $h$ into the tropospheric column, destabilizing the atmosphere by vertical motion.

In deriving the framework, we consider the shallowmode vertical advection $V_{h}^{s}$ as part of the forcing by including it into an effective "heating" term $Q=F_{\text {sen }}+$ $F_{\text {lat }}+R+H+V_{h}^{s}$. In doing so, we follow the reasoning by Chou et al. (2013) in that the destabilizing effect of shallow circulations is responsible for the import of column $h$, which the deep convection responds to. The total horizontal advection of $h, H=H_{m}+H_{e}$, is given by the sum of mean (subscript " $m$ ") and eddy (subscript " $e$ ") horizontal advection. While $H_{m}$ is directly computed from monthly mean model fields, the nonnegligible $H_{e}$ (e.g., Peters et al. 2008) is estimated as residual from the budget in Eq. (2). This assumption was tested and found to be justified for the MPI-CM5LR simulations for which more output could be generated. Combining Eqs. (2) and (4) yields a framework to diagnose the vertically averaged vertical velocity of the assumed deep overturning mode,

$$
\bar{\omega}^{v}=-\frac{Q}{\Gamma_{d}}=-\beta Q,
$$

thus introducing $\beta$ as the inverse gross moist stability.

To be well posed, the deep-mode structure $\phi_{d}(p)$ must be defined such that $\Gamma_{d}$ is positive for all tropical latitudes, conforming to the physical consideration that heating (positive $Q$ ) is associated with large-scale ascent (negative $\omega_{d}$ ) in Eq. (5). Here, $\phi_{d}(p)$ is represented by a beta distribution,

$$
\phi_{d}(p)= \begin{cases}\frac{\left(p_{s}-p_{t}\right)\left(p-p_{t}\right)^{a-1}\left(p_{s}-p\right)^{b-1}}{B\left(p_{s}, p_{t}, a, b\right)}, & p_{t} \leq p \leq p_{s} \\ 0, & \text { otherwise }\end{cases}
$$

with $p_{s}=1000 \mathrm{hPa}, p_{t}=100 \mathrm{hPa}, B\left(p_{s}, p_{t}, a, b\right)=$ $[\Gamma(a) \Gamma(b) / \Gamma(a+b)]\left(p_{s}-p_{t}\right)^{a+b-1}$, and $\Gamma$ the gamma function. The shape parameters $(a=2$ and $b=3)$ yield a deep-mode structure that places the maximum vertical velocity at approximately $400 \mathrm{hPa}$ (see Fig. S2). Because the column vertical advection of $h$ is sensitive to the chosen integration levels (e.g., Chou et al. 2013; Bui et al. 2016) we adopt a definition of the deep mode over the depth of the troposphere defined for each grid point and model, rather than in terms of predetermined pressure levels. Further, the above definition assures that $\left\langle\phi_{d}(p)\right\rangle=1$. We have additionally tested different forms of $\phi_{d}(p)$ (see, e.g., Fig. S2), and though they yield different values for $\Gamma_{d}$ and $V_{h}^{s}$, they do not affect the main conclusions arising from the following analysis.

\section{Are intermodel differences governed by the gross moist stability or the heating?}

With the help of the moist static energy framework described in the previous section, we aim at identifying which terms in Eq. (5) can best explain the intermodel spread in $\bar{\omega}^{v}$. For simplicity we drop the $\left(\ulcorner)^{v}\right.$ in the following. All analysis is performed in terms of zonalmean quantities, and hence the results only vary with latitude $\varphi$. For each model $i$, we decompose $\omega_{i}(\varphi)=$ $\bar{\omega}(\varphi)+\omega_{i}^{\prime}(\varphi)$ into the multimodel mean (denoted by the overline) and the anomaly from the multimodel mean (denoted by a prime). We keep the subscript $i$ for the primed terms to maintain the association with an individual model, but drop the explicit reference to latitude in what follows. We treat the model's heating $Q_{i}$ and inverse gross moist stability $\beta_{i}$ in the same way. Then the anomalous vertical velocity from Eq. (5) can be written by expanding each of the $\beta_{i}$ and $Q_{i}$ into their constituent parts, such that,

$$
-\omega_{i}^{\prime}=\beta_{i}^{\prime} \bar{Q}+\bar{\beta} Q_{i}^{\prime}+\beta_{i}^{\prime} Q_{i}^{\prime}=-\overline{\beta_{i}^{\prime} Q_{i}^{\prime}} .
$$

The last term, by virtue of being averaged over the models, is a constant.

This decomposition then allows us to ask which terms are most important for intermodel differences in the vertical velocity and hence precipitation. As shown in 
Fig. 7, variations in $\omega_{i}^{\prime}$ are effectively carried by the heating anomalies, that is, the $\bar{\beta} Q_{i}^{\prime}$ term. Variations in the stability, as measured by $\beta_{i}^{\prime}$ terms, are comparatively small so that terms involving $\beta_{i}^{\prime}$ have little relation to $\omega_{i}^{\prime}$. In other words, stability variations are not important for explaining variation in the zonal-mean vertical velocity (and therefore not shown)-rather, intermodel differences in vertical-velocity scale with intermodel differences in the effective heating.

Next, we investigate which of the individual heating terms in $Q$ best explains the models' zonal-mean $\omega$. For this, the contribution to $\omega$ from each heating term $Q_{j}$, such that $Q_{j} \in\left\{F_{\text {sen }}, F_{\text {lat }}, R, H_{e}, H_{m}, V_{h}^{s}\right\}$, and the model's own inverse gross moist stability $\beta$ is separately predicted via Eq. (5). The contributions are compared to the models' zonal-mean $\omega$ in Fig. 8. The sensible heat flux only weakly heats the atmospheric column homogeneously over the tropics and therefore is not indicative of differences in $\omega$ across models. The latent heat flux does appear to have an impact on the vertical velocity as predictions follow the direction of the one-to-one line, but with an offset because $F_{\text {lat }}$ is positive throughout the tropics and therefore fails to predict subsidence. Radiation exports $h$ from the column by radiative cooling, thus only predicting subsidence motion. Radiative cooling and latent heating work against each other, though also $Q_{j}=F_{\text {lat }}+R$ does not satisfactorily explain $\omega$ (not shown). Both horizontal advection terms mainly export moist static energy from the column and fail to predict $\omega$ well.

Of all the heating terms, the residual (shallow mode) vertical advection best explains $\omega_{i}^{\prime}$ (Fig. 8f), with predictions centered on the one-to-one line. Consequently, the root-mean-square errors of the prediction are small, with a multimodel mean of $7.3 \mathrm{hPa} \mathrm{day}^{-1}$. This implies that explaining differences in the circulations across the models depends on each model's residual circulation from the assumed deep mode, something we interpret as a separate shallow mode. How much of the intermodel spread is explained by the shallow circulation depends on the assumed structure for the deep mode.

Incorporating more of the shallow circulation within the definition of the deep mode by adopting a less topheavy vertical motion structure leads to less of a role for the shallow mode (as measured by a greater multimodelmean RMSE; Fig. S3). However, such a profile does not define a positive $\Gamma_{d}$ across all experiments. Although the models, and perhaps convective parameterization differences, would have been easier to understand if their differences could have been related to how strongly the convection couples to surface or radiative fluxes, this does not follow from our analysis, as the circulationconvection coupling appears to be the dominant difference among the models.

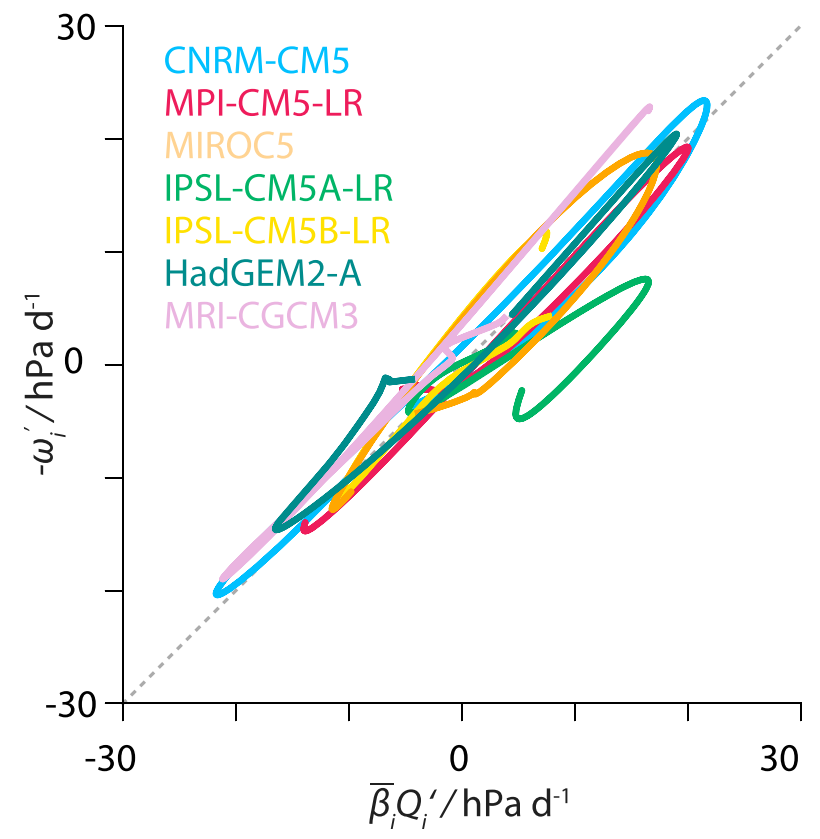

FIG. 7. Anomalous vertical-mean vertical velocity vs the contribution from anomalous heating $\bar{\beta} Q_{i}^{\prime}$. Note that zonal means are symmetrized between both hemispheres, such that endpoints of the lines correspond to $\varphi=0^{\circ}$ and $\varphi= \pm 30^{\circ}$, respectively.

\section{The shallow circulation in moisture space}

To gain a better understanding of moist static energy advection by the shallow circulation and how it differs among the models, we take a closer look at the shallow circulation in moisture space in the ACRE-off experiment. The moisture space sorts variables by the amount of column moisture spanning from dry to moist columns. Whereas the models' moisture distributions are similar at the dry end (Fig. 9), they strongly differ in the amount of integrated water vapor (IWV) at the moist end. That the peak of high IWV varies between about $34 \mathrm{~kg} \mathrm{~m}^{-2}$ in the IPSL-CM5A-LR model and $50 \mathrm{~kg} \mathrm{~m}^{-2}$ in MRICGCM3 indicates a different sensitivity to moisture in the models' convection schemes. Models with low sensitivity to environmental moisture convect easily even in dry environments (Möbis and Stevens 2012). Indeed, models with lower values at the moist peak tend to place their ITCZ more poleward in drier environments than those with higher values. This can be seen by comparing the CNRM-CM5 or MIROC5 precipitation distribution with that of MRI-CGCM3 in Fig. 1b. Because the models' moisture distributions are so diverse, we use percentiles of IWV as the binning variable for the moisture space to allow a better comparison among models. Temperature gradients are weak in the tropics (e.g., Sobel et al. 2001), such that the moisture space can be thought of spanning from areas of low-column $h$ at 
a)
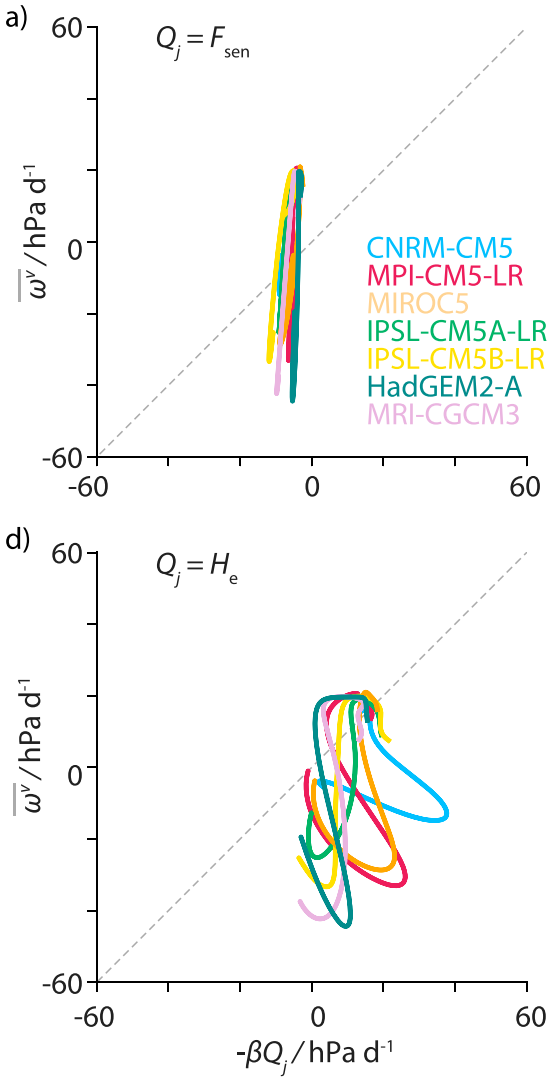

b)

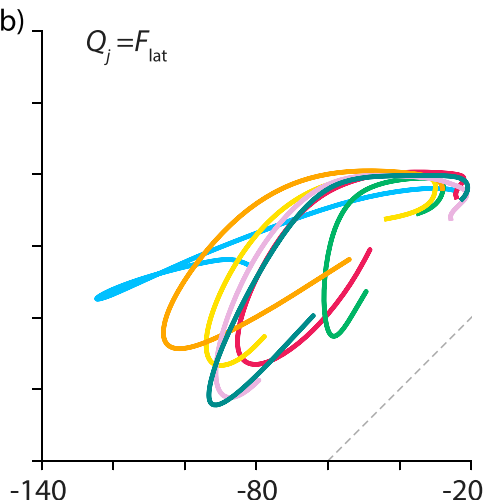

e)

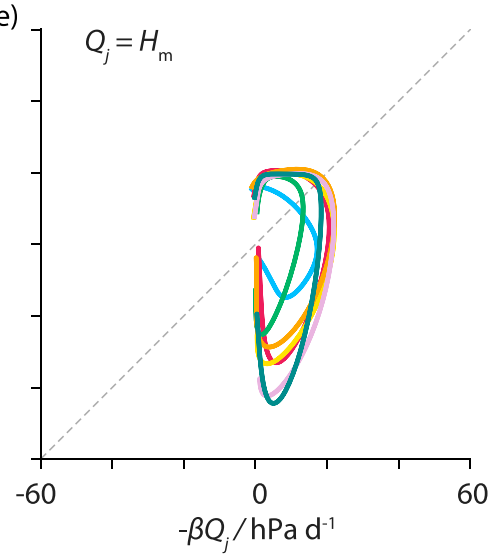

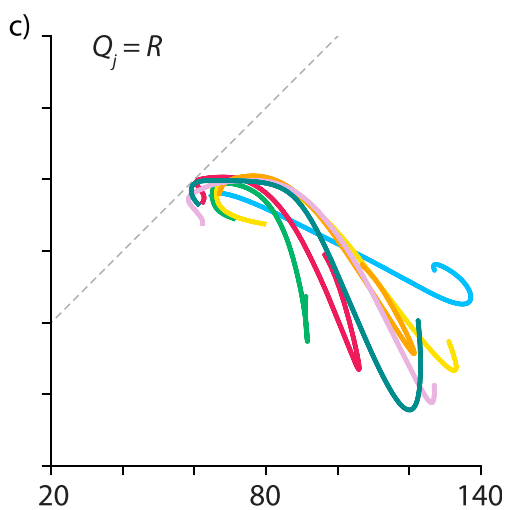

f)

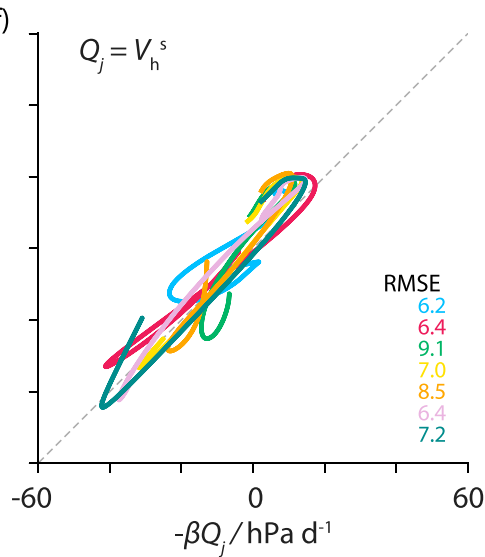

FIG. 8. Relationship between the zonal-mean $\bar{\omega}^{v}$ from the models and that predicted using Eq. (5) with each model's own gross moist stability and some subset of the contributions to $Q_{j}$ : (a) sensible heat flux, (b) latent heat flux, (c) radiative heating, (d) horizontal eddy advection, (e) horizontal mean advection, and (f) shallow-mode vertical advection. Note that zonal means are symmetrized between both hemispheres, such that endpoints of the lines where $\bar{\omega}^{v}$ is negative correspond to the equator and positive endpoints to $\pm 30^{\circ}$. In (f) the RMSE is shown for the individual models.

the dry end to high-column $h$ at the moist end and with that essentially from the dry subtropics to the location of the ITCZ.

Circulations in moisture space can be thought of as motion along moisture gradients. Figure 10 shows the total and shallow circulations in moisture space as streamlines constructed from the vertical velocity following Bretherton et al. (2005). The streamlines are assumed to close at the moist end (as in Bretherton and Khairoutdinov 2015), which corresponds to the deep tropics and which lies indisputably within the tropical analysis $\left( \pm 30^{\circ}\right)$ domain. Streamlines may not close at the dry end as the system is open to mass exchange at the boundaries of this analysis domain. For the total circulations, the model vertical velocity $\omega(p)$ is used whereas the shallow circulations arise from the shallow-mode vertical velocity $\omega_{s}(p)$.

Generally, the circulations are weaker for models with a more poleward ITCZ, as was also discussed with respect to Fig. 5. If the strength of the circulation is defined as the minimum streamfunction value, then the strength correlates strongly with the ITCZ position ( $R^{2}=0.88$ for the total and $R^{2}=0.83$ for the shallow circulation). In all models, shallow circulations emerge. They indicate a lower branch of the total circulation

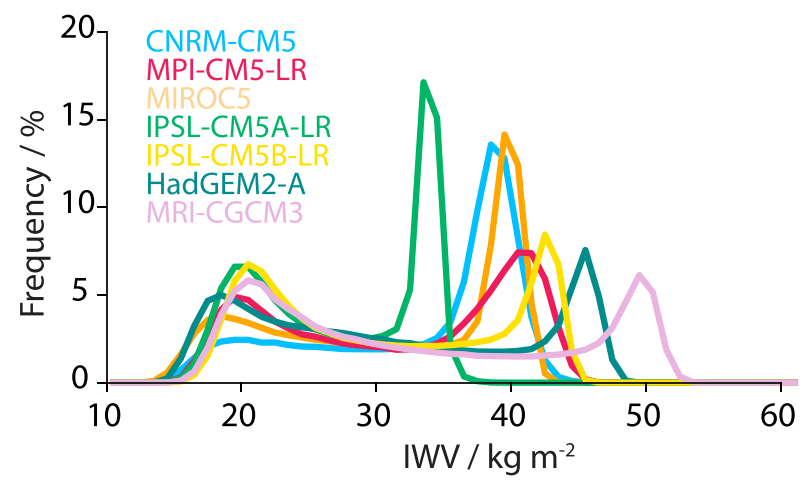

FIG. 9. Frequency distribution of monthly mean IWV in the tropics of the control ACRE-off experiment, binned by $1 \mathrm{~kg} \mathrm{~m}^{-2}$. 


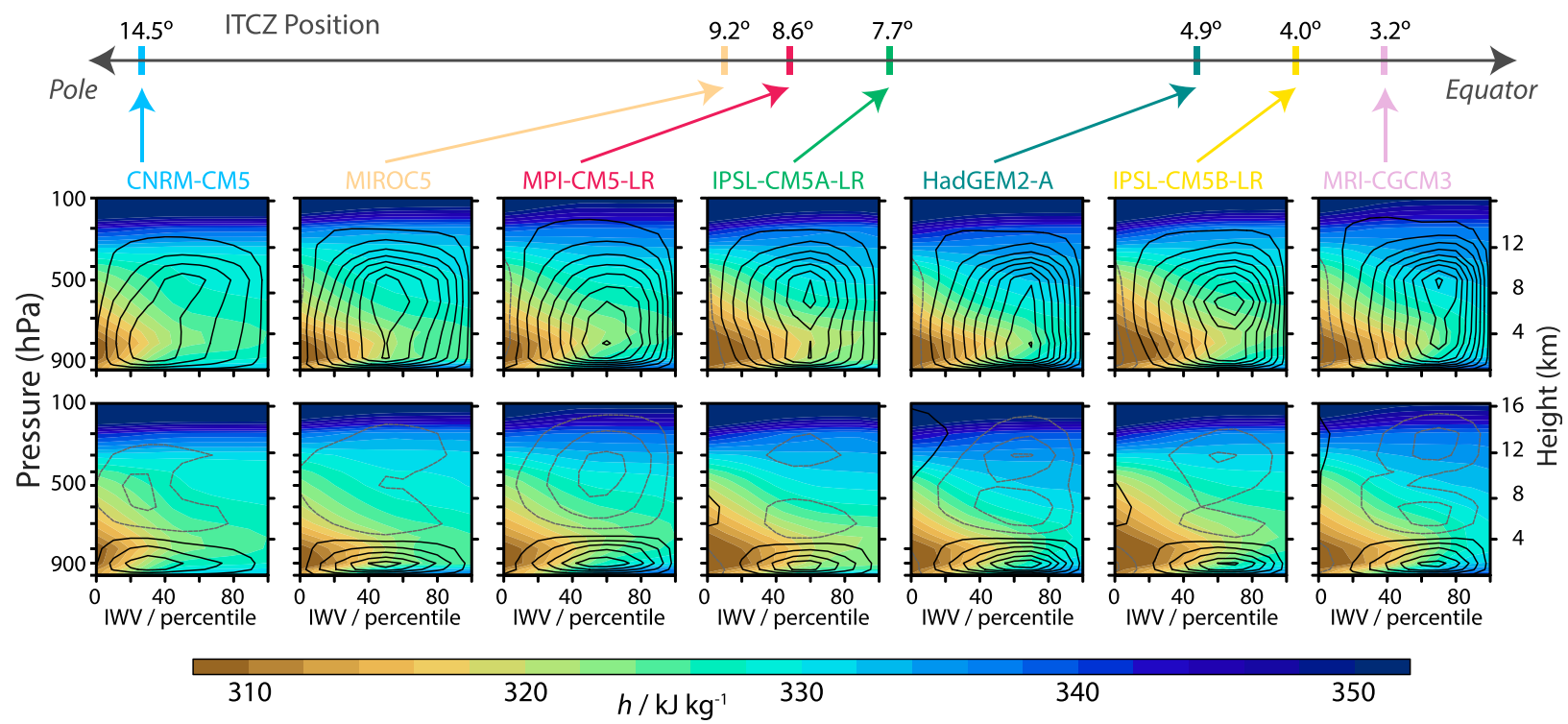

FIG. 10. (top) Total and (bottom) shallow circulation in moisture space, which is spanned by the percentiles of IWV. The control ACREoff experiment is shown. The models are ordered by their ITCZ position. Deciles of IWV are chosen as bin borders (i.e., 0th, 10th, 20th, ... , 100 th) and moist static energy (shading) is averaged within those bins. The streamfunction $\Psi$ is constructed following Bretherton et al. (2005) but is assumed to close at the moist end $\left(\Psi_{n}=0\right)$ and includes bin weighting to remove the dependence on bin size of the streamfunction. For $n$ bins, the streamfunction defined at the border is given by $\Psi_{n-i}=\Psi_{n+1-i}+g^{-1} \alpha_{n-i / 2} \omega_{n-i / 2}(p)$, with $i=1,2, \ldots, n$. The variable $\omega_{n-i / 2}$ refers to the average vertical velocity in the given bin, and $\alpha_{n-i / 2}$ holds the normalized area weights such that $\sum \alpha_{n-i / 2}=1$. Streamline contours are drawn at intervals of $0.2 \mathrm{~g} \mathrm{~m}^{-2} \mathrm{~s}^{-1}$ starting at $\pm 0.1 \mathrm{~g} \mathrm{~m}^{-2} \mathrm{~s}^{-1}$. Negative (black solid lines) values indicate a counterclockwise circulation and positive (gray dashed lines) a clockwise circulation.

where low $h$ is transported near the surface toward moist areas just as in the total circulation. Important for the net import or export of $h$ into the atmospheric column, however, is the vertical integral of moist static energy advection. Because the shallow and the total circulation differ in the return branch, they have a different impact on the import or export of column $h$ across the moisture space. The return branch of the total circulation is located at the top of the troposphere where horizontal gradients of $h$ are small and vertical gradients similar in the dry and moist end. On the contrary, the return branch of the shallow circulation occurs at a height of approximately $4 \mathrm{~km}$. This is the height where moist static energy approximately minimizes and differences across the moisture space maximize, ranging from about 305 to $325 \mathrm{~kJ} \mathrm{~kg}^{-1}$ at the dry and moist ends, respectively. Whereas the height of the return branch is similar among models, the location in moisture space where shallow motion switches sign from subsidence to convection ranges from approximately the 40th to the 70th percentile of IWV. This again indicates that the shallow circulation embedded within the total circulation couples differently to moisture gradients among the models.

The horizontal and vertical advection by the total and shallow circulation is quantified in terms of mass-weighted vertical integrals in Fig. 11. The vertical advection by the total and shallow circulation differs in their impacts on the moisture variance. The vertical advection of the total circulation mainly imports moist static energy at the dry end with almost no import or export at the moist end. With that, the vertical advection by the total circulation homogenizes differences in column $h$ across the moisture space and effectively damps the variance of moisture within the domain. On the contrary, the shallow-mode vertical advection increases column $h$ differences by removing $h$ from dry regions and adding $h$ to moist regions. The fact that the total circulations differ in moisture space is indicative of the importance of shallow circulations in conditioning the atmosphere for deep convection.

This countergradient transport of $h$ by the shallow circulation is currently regarded as one of the main processes for self-aggregation found in idealized radiativeconvective equilibrium model simulations (for a review see Wing et al. 2017). Our results from experiments with inactive cloud-radiation interaction indicate that different coupling of the shallow circulation to moisture in the models, in particular the shallow-mode vertical advection, may also be the primary factor for driving intermodel differences in the zonal-mean distribution of vertical velocity and precipitation. 

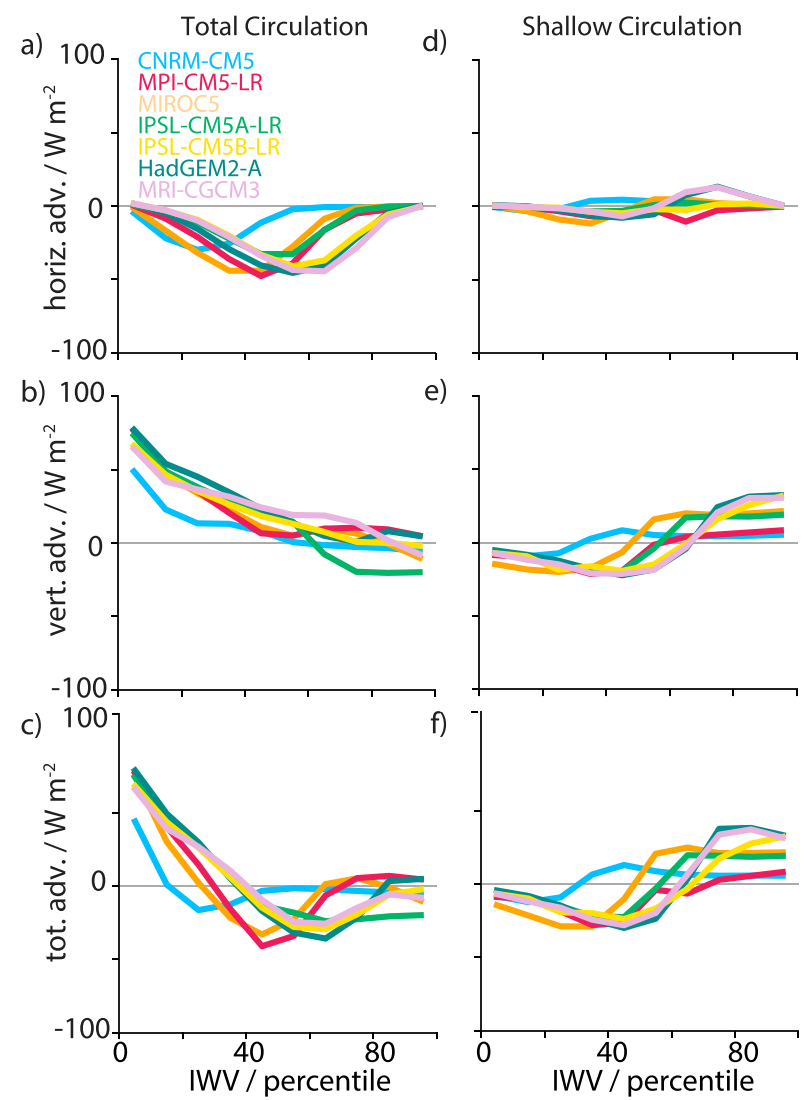

FIG. 11. Vertically integrated horizontal and total advection in moisture space of moist static energy by the (a)-(c) total and (d)-(f) shallow circulation in the control ACRE-off experiment. Note that, for the shallow circulation, only areas are included in the vertSsical integral where the shallow streamfunction is negative in the lower troposphere. Positive signs signify a net import of $h$ into the column.

\section{Summary and conclusions}

To elucidate the causes of intermodel spread in the tropical precipitation distribution and its response to warming, we explore aquaplanet simulations from the Clouds On-Off Klimate Intercomparison Experiment (COOKIE; Stevens et al. 2012). Seven models provide the simulations for a control climate with fixed sea surface temperatures and a warmed state where sea surface temperatures are uniformly raised by $4 \mathrm{~K}$. In these simulations, atmospheric cloud radiative effects (ACREs) are either active (ACRE-on) or inactive (ACRE-off). Patterns of tropical precipitation are identified based on a subset of five precipitation indicators defined by Popp and Lutsko (2017) as determined using cubic-spline fits to each simulation's zonal- and timemean precipitation fields. Past work comparing two models identified ACRE changes as the main cause of differences in tropical precipitation changes with warming (Voigt and Shaw 2015). This leads us to hypothesize that by removing the cloud-radiation interaction, models should produce less diversity in their precipitation patterns and change in these patterns with warming.

Our analysis is consistent with that by Voigt and Shaw (2015) in that the two models they analyze-which incidentally have the most divergent response to warmingdiffer less in their response to warming when ACREs are inactive. This result does not, however, generalize. When looking across a larger set of models, we find that changes in patterns of tropical precipitation with warming tend to be dampened in the absence of ACREs, but the direction of the changes are, if anything, more diverse in the absence cloud radiative effects.

Consistent with earlier studies (Crueger and Stevens 2015; Harrop and Hartmann 2016; Popp and Silvers 2017) we find that ACREs cause a more prominent equatorial precipitation feature, which in many cases can be interpreted in terms of an equatorward shift of the ITCZ. Our analysis demonstrates that this tendency is also present in warmer climates. We additionally find that while models respond robustly to the inclusion of cloud radiative effects, these effects do not lead to more consistent patterns of modeled precipitation. In terms of the position of the ITCZ and the subtropical precipitation minima, models diverge more in the absence of cloud radiative effects than when ACREs are active.

A number of earlier studies have explored factors that influence the width, or equatorial expression, of the tropical rainbands (e.g., Bretherton and Sobel 2002; Chou and Neelin 2004; Byrne and Schneider 2016). Among these Harrop and Hartmann (2016) and Popp and Silvers (2017) specifically focus on the role of cloud radiative effects. Harrop and Hartmann (2016) introduce a mechanism based on the convective available potential energy (CAPE) to explain the equatorward ITCZ shift in ACRE-on. They argue that the direct heating effect from clouds increases the upper-tropospheric temperature tropics-wide, which decreases CAPE. Smaller CAPE implies an environment less supportive of deep convection. High CAPE values then are confined closer to the equator, which contracts the ITCZs toward the equator. However, their conclusions neglect the fact that the equatorward ITCZ shift itself causes an increase of upper-tropospheric temperatures as they are coupled to the surface temperature in deep convective areas through the moist adiabat (e.g., Johnson and Xie 2010). It is unclear if the observed contraction of high CAPE values in ACRE-on is the cause of the ITCZ shift or a combination of cloud radiative heating and the ITCZ shift itself. Popp and Silvers (2017) propose a dynamic argument: loud radiative heating enhances the atmospheric energy uptake in the deep tropics, 
entailing a strengthening of the Hadley circulation. Consequently, surface winds increase off the equator, enhancing the countergradient import of weak low-level moist static energy that shifts the peak in low-level moist static energy and hence the ITCZ equatorward. At some level, however, and as evident from earlier studies (Möbis and Stevens 2012; Becker et al. 2017), the tight coupling between convection and the large-scale flow makes it difficult to assess causality from balances in budgets.

The tight coupling between precipitation and the large-scale flow, as measured by the vertically averaged large-scale vertical velocity, implies that this velocity should be strongly related to precipitation across models and experiments. This expectation is confirmed in our analysis and motivates us to measure differences in the tropical circulation across models in terms of their distribution of their large-scale vertical velocity. Given the closeness of the relationship between vertical velocity and precipitation, it was to be expected that spatial features of the large-scale circulations would differ among models, more so in the ACRE-off simulations. This is indeed the case. What was not expected was the degree to which the simulations differed not just in the spatial distribution of large-scale vertical velocity but in the distribution as a whole, as sampled across the tropics. Differences become particularly pronounced in the area between the double ITCZs in the ACRE-off simulations. In ACRE-off simulations, as less precipitation falls on the equator, models agree better in this quantity. As a whole, however, our results indicate that cloudradiation interaction is indeed not a major source for intermodel differences, rather it constrains the distribution of precipitation in the tropics.

To better understand reasons for intermodel differences in the absence of cloud-radiation interaction, we adopted a simple framework from the budget of moist static energy in stationarity. This approach takes advantage of the close relationship between the verticalmean vertical-velocity and the precipitation amount. It has been used in a number of previous studies, as it provides a basis for understanding how energetic drivers of the large-scale circulation are related to the circulation itself. The framework is most informative if it can be assumed that the tropical circulation can be represented by a deep circulation associated with a deep-mode vertical-velocity profile, because then the framework relates the strength of the circulation to the different inputs of energy into the column and the stability of the column. This stability, termed the gross moist stability (e.g., Neelin and Held 1987), is represented by the normalized vertical advection associated with the deep-mode vertical velocity. For our analysis, we model the deepmode vertical velocity as a top-heavy beta distribution profile with maximum vertical velocity at approximately $400 \mathrm{hPaday}^{-1}$. This choice is necessary to ensure that gross moist stabilities are positive across the tropics with minimum values in the deep tropics in the vicinity of deep convection. Deviations of the vertical velocity from the deep mode are retained as a column heating by shallow-mode vertical advection of moist static energy. Besides this, the column heating terms include the surface sensible and latent heat fluxes, the atmospheric radiative flux divergence, and the horizontal advection of moist static energy. For decompositions allowing for a positive gross moist stability across models and experiments, the shallow-mode vertical advection best explains intermodel differences in the zonal-mean vertical-velocity distribution, while the other heating terms as well as the deepmode gross moist stability play minor roles. This suggests that intermodel differences in precipitation and circulation cannot be understood by considering only the deep overturning circulation and its diabatic drivers. The importance of other modes of circulation is also supported by a moisture space analysis. It shows that the shallowmode vertical advection imports moist static energy from dry to moist areas. This enhances moisture variances across the tropics and supplies energy for deep convection into areas with low gross moist stability, consequently driving the deep circulation. This interplay seems crucial for deciding the eventual distribution of precipitation across models.

While undoubtedly cloud-radiation interaction has a fundamental impact on the organization of the tropical circulation and precipitation distribution, in particular the location of the ITCZ, intermodel differences still persist or are accentuated when cloud-radiation interaction is inactive. Differences in the location of the ITCZ imply a different degree of convective aggregation among models. Studies of radiative-convective equilibrium identify the countergradient transport of column $h$ by shallow circulations (for a review see Wing et al. 2017) as an important driver for convective aggregation. Our results from the simple deep-mode framework of the vertical velocity applied to the ACRE-off experiment show that the vertical advection by shallow circulations is central for explaining intermodel differences but cannot be directly attributed to cloud radiative effects. How models couple shallow circulations to moisture gradients may thus not only be important for convective aggregation in idealized radiative-convective equilibrium studies but also in a more Earth-like tropical setting.

Acknowledgments. We acknowledge CFMIP for coordinating the COOKIE initiative and the individual modeling centers for running the simulations and providing 
the model output. We thank Hauke Schulz and Max Popp for useful discussions, as well as Traute Crueger for helpful comments on an earlier version of this manuscript. Penelope Maher and two anonymous reviewers made constructive suggestions that considerably improved the manuscript. This research was supported by the Max-Planck-Gesellschaft (MPG), and computational resources were made available by Deutsches Klimarechenzentrum (DKRZ). SB acknowledges support by the European Research Council (Grant 694768).

\section{REFERENCES}

Back, L. E., and C. S. Bretherton, 2006: Geographic variability in the export of moist static energy and vertical motion profiles in the tropical Pacific. Geophys. Res. Lett., 33, L17810, https:// doi.org/10.1029/2006GL026672.

Barsugli, J., S.-I. Shin, and P. D. Sardeshmukh, 2005: Tropical climate regimes and global climate sensitivity in a simple setting. J. Atmos. Sci., 62, 1226-1240, https://doi.org/10.1175/ JAS3404.1.

Becker, T., B. Stevens, and C. Hohenegger, 2017: Imprint of the convective parameterization and sea-surface temperature on large-scale convective self-aggregation. J. Adv. Model. Earth Syst., 9, 1488-1505, https://doi.org/10.1002/2016MS000865.

Bergman, J. W., and H. H. Hendon, 2000: Cloud radiative forcing of the low-latitude tropospheric circulation: Linear calculations. J. Atmos. Sci., 57, 2225-2245, https://doi.org/10.1175/ 1520-0469(2000)057<2225:CRFOTL > 2.0.CO;2.

Bjerknes, J., 1938: Saturated-adiabatic ascent of air through dryadiabatically descending environment. Quart. J. Roy. Meteor. Soc., 64, 325-330.

Bony, S., and J.-L. Dufresne, 2005: Marine boundary layer clouds at the heart of tropical cloud feedback uncertainties in climate models. Geophys. Res. Lett., 32, L20806, https://doi.org/ 10.1029/2005GL023851.

,-- , H. Le Treut, J.-J. Morcrette, and C. Senior, 2004: On dynamic and thermodynamic components of cloud changes. Climate Dyn., 22, 71-86, https://doi.org/10.1007/ s00382-003-0369-6.

- , G. Bellon, D. Klocke, S. Sherwood, S. Fermepin, and S. Denvil, 2013: Robust direct effect of carbon dioxide on tropical circulation and regional precipitation. Nat. Geosci., 6 , 447-451, https://doi.org/10.1038/ngeo1799; Corrigendum, 7, 547, https://doi.org/10.1038/ngeo2192.

Bretherton, C. S., and A. H. Sobel, 2002: A simple model of a convectively coupled Walker circulation using the weak temperature gradient approximation. J. Climate, 15, 2907-2920, https://doi.org/ 10.1175/1520-0442(2002)015<2907:ASMOAC >2.0.CO;2.

_ , and M. F. Khairoutdinov, 2015: Convective self-aggregation feedbacks in near-global cloud-resolving simulations of an aquaplanet. J. Adv. Model. Earth Syst., 7, 1765-1787, https:// doi.org/10.1002/2015MS000499.

— , P. N. Blossey, and M. Khairoutdinov, 2005: An energybalance analysis of deep convective self-aggregation above uniform SST. J. Atmos. Sci., 62, 4273-4292, https://doi.org/ 10.1175/JAS3614.1.

Bui, H. X., J.-Y. Yu, and C. Chou, 2016: Impacts of vertical structure of large-scale vertical motion in tropical climate: Moist static energy framework. J. Atmos. Sci., 73, 4427-4437, https://doi.org/10.1175/JAS-D-16-0031.1.
Byrne, M. P., and T. Schneider, 2016: Energetic constraints on the width of the intertropical convergence zone. J. Climate, 29, 4709-4721, https://doi.org/10.1175/JCLI-D-15-0767.1.

Cess, R. D., and Coauthors, 1990: Intercomparison and interpretation of climate feedback processes in 19 atmospheric general circulation models. J. Geophys. Res., 95, 1660116 615, https://doi.org/10.1029/JD095iD10p16601.

Chou, C., and J. D. Neelin, 2004: Mechanisms of global warming impacts on regional tropical precipitation. J. Climate, 17, 2688-2701, https://doi.org/10.1175/1520-0442(2004)017<2688: MOGWIO $>2.0 . \mathrm{CO} ; 2$.

— T.-C. Wu, and P.-H. Tan, 2013: Changes in gross moist stability in the tropics under global warming. Climate Dyn., 41, 2481-2496, https://doi.org/10.1007/s00382-013-1703-2.

Collins, W. J., and Coauthors, 2011: Development and evaluation of an Earth-system model-HadGEM2. Geosci. Model Dev., 4, 1051-1075, https://doi.org/10.5194/gmd-4-1051-2011.

Coppin, D., and S. Bony, 2015: Physical mechanisms controlling the initiation of convective self-aggregation in a general circulation model. J. Adv. Model. Earth Syst., 7, 2060-2078, https://doi.org/10.1002/2015MS000571.

Crueger, T., and B. Stevens, 2015: The effect of atmospheric radiative heating by clouds on the Madden-Julian oscillation. J. Adv. Model. Earth Syst., 7, 854-864, https://doi.org/10.1002/ 2015MS000434.

Dahms, E., H. Borth, F. Lunkeit, and K. Fraedrich, 2011: ITCZ splitting and the influence of large-scale eddy fields on the tropical mean state. J. Meteor. Soc. Japan, 89, 399-411, https:// doi.org/10.2151/jmsj.2011-501.

Dufresne, J.-L., and Coauthors, 2013: Climate change projections using the IPSL-CM5 Earth System Model: From CMIP3 to CMIP5. Climate Dyn., 40, 2123-2165, https://doi.org/10.1007/ s00382-012-1636-1.

Fermepin, S., and S. Bony, 2014: Influence of low-cloud radiative effects on tropical circulation and precipitation. J. Adv. Model. Earth Syst., 6, 513-526, https://doi.org/10.1002/2013MS000288.

Harrop, B. E., and D. L. Hartmann, 2016: The role of cloud radiative heating in determining the location of the ITCZ in aquaplanet simulations. J. Climate, 29, 2741-2763, https:// doi.org/10.1175/JCLI-D-15-0521.1.

Hartmann, D. L., and K. Larson, 2002: An important constraint on tropical cloud-climate feedback. Geophys. Res. Lett., 29, 1951, https://doi.org/10.1029/2002GL015835.

Hawkins, E., and R. Sutton, 2011: The potential to narrow uncertainty in projections of regional precipitation change. Climate Dyn., 37, 407-418, https://doi.org/10.1007/s00382-010-0810-6.

Hourdin, F., and Coauthors, 2013: LMDZ5B: The atmospheric component of the IPSL climate model with revisited parameterizations for clouds and convection. Climate Dyn., 40, 2193-2222, https://doi.org/10.1007/s00382-012-1343-y.

Inoue, K., and L. E. Back, 2015a: Column-integrated moist static energy budget analysis on various time scales during TOGA COARE. J. Atmos. Sci., 72, 1856-1871, https://doi.org/10.1175/ JAS-D-14-0249.1.

— , and — 2015b: Gross moist stability assessment during TOGA COARE: Various interpretations of gross moist stability. J. Atmos. Sci., 72, 4148-4166, https://doi.org/10.1175/ JAS-D-15-0092.1.

Johnson, N. C., and S.-P. Xie, 2010: Changes in the sea surface temperature threshold for tropical convection. Nat. Geosci., 3, 842-845, https://doi.org/10.1038/ngeo1008.

Kirtman, B. P., and E. K. Schneider, 2000: A spontaneously generated tropical atmospheric general circulation. J. Atmos. Sci., 
57, 2080-2093, https://doi.org/10.1175/1520-0469(2000)057<2080: ASGTAG $>2.0$. CO; 2 .

Knutti, R., and J. Sedláček, 2013: Robustness and uncertainties in the new CMIP5 climate model projections. Nat. Climate Change, 3, 369-373, https://doi.org/10.1038/nclimate1716.

Landu, K., L. R. Leung, S. Hagos, V. Vinoj, S. A. Rauscher, T. Ringler, and M. Taylor, 2014: The dependence of ITCZ structure on model resolution and dynamical core in aquaplanet simulations. J. Climate, 27, 2375-2385, https://doi.org/ 10.1175/JCLI-D-13-00269.1.

Li, Y., D. W. J. Thompson, and S. Bony, 2015: The influence of atmospheric cloud radiative effects on the large-scale atmospheric circulation. J. Climate, 28, 7263-7278, https://doi.org/ 10.1175/JCLI-D-14-00825.1.

Liu, Y., L. Guo, G. Wu, and Z. Wang, 2010: Sensitivity of ITCZ configuration to cumulus convective parameterizations on an aqua planet. Climate Dyn., 34, 223-240, https://doi.org/ 10.1007/s00382-009-0652-2.

Mauritsen, T., R. G. Graversen, D. Klocke, P. L. Langen, B. Stevens, and L. Tomassini, 2013: Climate feedback efficiency and synergy. Climate Dyn., 41, 2539-2554, https://doi.org/10.1007/ s00382-013-1808-7.

Medeiros, B., B. Stevens, and S. Bony, 2015: Using aquaplanets to understand the robust responses of comprehensive climate models to forcing. Climate Dyn., 44, 1957-1977, https://doi.org/ 10.1007/s00382-014-2138-0.

Möbis, B., and B. Stevens, 2012: Factors controlling the position of the intertropical convergence zone on an aquaplanet. J. Adv. Model. Earth Syst., 4, M00A04, https://doi.org/10.1029/ 2012MS000199.

Neale, R. B., and B. J. Hoskins, 2000: A standard test for AGCMs including their physical parametrizations: I: The proposal. Atmos. Sci. Lett., 1, 101-107, https://doi.org/10.1006/ asle.2000.0019.

Neelin, J. D., and I. M. Held, 1987: Modeling tropical convergence based on the moist static energy budget. Mon. Wea. Rev., 115, 3-12, https://doi.org/10.1175/1520-0493(1987)115<0003: MTCBOT>2.0.CO;2.

—, and N. Zeng, 2000: A quasi-equilibrium tropical circulation model-Formulation. J. Atmos. Sci., 57, 1741-1766, https:// doi.org/10.1175/1520-0469(2000)057<1741:AQETCM>2.0.CO;2.

Numaguti, A., 1993: Dynamics and energy balance of the Hadley circulation and the tropical precipitation zones: Significance of the distribution of evaporation. J. Atmos. Sci., 50, 1874-1887, https://doi.org/10.1175/1520-0469(1993)050<1874: DAEBOT $>2.0 . \mathrm{CO} ; 2$.

Oueslati, B., and G. Bellon, 2013a: Convective entrainment and large-scale organization of tropical precipitation: Sensitivity of the CNRM-CM5 hierarchy of models. J. Climate, 26, 29312946, https://doi.org/10.1175/JCLI-D-12-00314.1.

$\longrightarrow$, and,$- 2013 \mathrm{~b}$ : Tropical precipitation regimes and mechanisms of regime transitions: Contrasting two aquaplanet general circulation models. Climate Dyn., 40, 2345-2358, https:// doi.org/10.1007/s00382-012-1344-x.

— - S. Bony, C. Risi, and J.-L. Dufresne, 2016: Interpreting the inter-model spread in regional precipitation projections in the tropics: Role of surface evaporation and cloud radiative effects. Climate Dyn., 47, 2801-2815, https://doi.org/10.1007/ s00382-016-2998-6.

Peters, M. E., Z. Kuang, and C. C. Walker, 2008: Analysis of atmospheric energy transport in ERA-40 and implications for simple models of the mean tropical circulation. J. Climate, 21, 5229-5241, https://doi.org/10.1175/2008JCLI2073.1.
Popp, M., and N. J. Lutsko, 2017: Quantifying the zonal-mean structure of tropical precipitation. Geophys. Res. Lett., 44, 9470-9478, https://doi.org/10.1002/2017GL075235.

_ , and L. G. Silvers, 2017: Double and single ITCZs with and without clouds. J. Climate, 30, 9147-9166, https://doi.org/ 10.1175/JCLI-D-17-0062.1.

Ramanathan, V., 1987: The role of Earth radiation budget studies in climate and general circulation research. J. Geophys. Res., 92, 4075-4095, https://doi.org/10.1029/JD092iD04p04075.

Randall, D. A., Harshvardhan, D. A. Dazlich, and T. G. Corsetti, 1989: Interactions among radiation, convection, and largescale dynamics in a general circulation model. J. Atmos. Sci., 46, 1943-1970, https://doi.org/10.1175/1520-0469(1989)046<1943: IARCAL $>2.0 . \mathrm{CO} ; 2$.

Raymond, D. J., S. L. Sessions, A. H. Sobel, and Ž. Fuchs, 2009: The mechanics of gross moist stability. J. Adv. Model. Earth Syst., 1, 9, https://doi.org/10.3894/JAMES.2009.1.9.

Shepherd, T. G., 2014: Atmospheric circulation as a source of uncertainty in climate change projections. Nat. Geosci., 7, 703708, https://doi.org/10.1038/ngeo2253.

Sherwood, S. C., V. Ramanathan, T. P. Barnett, M. K. Tyree, and E. Roeckner, 1994: Response of an atmospheric general circulation model to radiative forcing of tropical clouds. J. Geophys. Res., 99, 20 829-20 845, https://doi.org/10.1029/ 94JD01632.

Slingo, A., and J. M. Slingo, 1988: The response of a general circulation model to cloud longwave radiative forcing. I: Introduction and initial experiments. Quart. J. Roy. Meteor. Soc., 114, 1027-1062, https://doi.org/10.1002/qj.49711448209.

Slingo, J. M., and A. Slingo, 1991: The response of a general circulation model to cloud longwave radiative forcing. II: Further studies. Quart. J. Roy. Meteor. Soc., 117, 333-364, https:// doi.org/10.1002/qj.49711749805.

Sobel, A. H., J. Nilsson, and L. M. Polvani, 2001: The weak temperature gradient approximation and balanced tropical moisture waves. J. Atmos. Sci., 58, 3650-3665, https://doi.org/ 10.1175/1520-0469(2001)058<3650:TWTGAA >2.0.CO;2.

Stevens, B., and S. Bony, 2013: What are climate models missing? Science, 340, 1053-1054, https://doi.org/10.1126/ science.1237554.

— - , and M. Webb, 2012: Clouds On-Off Klimate Intercomparison Experiment (COOKIE). EUCLIPSE Tech. Rep., 12 pp., http://www.euclipse.eu/downloads/Cookie.pdf.

— , and Coauthors, 2013: Atmospheric component of the MPI-M Earth System Model: ECHAM6. J. Adv. Model. Earth Syst., 5, 146-172, https://doi.org/10.1002/jame.20015.

Tian, B., and V. Ramanathan, 2002: Role of tropical clouds in surface and atmospheric energy budget. J. Climate, $\mathbf{1 5}$, 296-305, https://doi.org/10.1175/1520-0442(2002)015<0296: ROTCIS $>2.0 . C O ; 2$.

Trenberth, K. E., D. P. Stepaniak, and J. M. Caron, 2000: The global monsoon as seen through the divergent atmospheric circulation. J. Climate, 13, 3969-3993, https://doi.org/10.1175/ 1520-0442(2000)013<3969:TGMAST>2.0.CO;2.

Vial, J., J.-L. Dufresne, and S. Bony, 2013: On the interpretation of inter-model spread in CMIP5 climate sensitivity estimates. Climate Dyn., 41, 3339-3362, https://doi.org/10.1007/ s00382-013-1725-9.

Voigt, A., and T. A. Shaw, 2015: Circulation response to warming shaped by radiative changes of clouds and water vapour. Nat. Geosci., 8, 102-106, https://doi.org/10.1038/ngeo2345.

_ S. Bony, J.-L. Dufresne, and B. Stevens, 2014: The radiative impact of clouds on the shift of the intertropical convergence 
zone. Geophys. Res. Lett., 41, 4308-4315, https://doi.org/ 10.1002/2014GL060354.

Voldoire, A., and Coauthors, 2013: The CNRM-CM5.1 global climate model: Description and basic evaluation. Climate Dyn., 40, 2091-2121, https://doi.org/10.1007/s00382-011-1259-y.

Watanabe, M., and Coauthors, 2010: Improved climate simulation by MIROC5: Mean states, variability, and climate sensitivity. J. Climate, 23, 6312-6335, https://doi.org/10.1175/2010JCLI3679.1.

Wetherald, R. T., and S. Manabe, 1988: Cloud feedback processes in a general circulation model. J. Atmos. Sci., 45, 1397-1416, https:// doi.org/10.1175/1520-0469(1988)045<1397:CFPIAG>2.0.CO;2.

Williamson, D. L., and Coauthors, 2013: The Aqua-Planet Experiment (APE): Response to changed meridional SST profile. J. Meteor. Soc. Japan, 91A, 57-89, https://doi.org/10.2151/ jmsj.2013-A03.

Wing, A. A., K. Emanuel, C. E. Holloway, and C. Muller, 2017: Convective self-aggregation in numerical simulations: A review. Surv. Geophys., 38, 1173-1197, https://doi.org/10.1007/ s10712-017-9408-4.
Xie, S.-P., and Coauthors, 2015: Towards predictive understanding of regional climate change. Nat. Climate Change, 5, 921-930, https://doi.org/10.1038/nclimate2689.

Yu, J.-Y., C. Chou, and J. D. Neelin, 1998: Estimating the gross moist stability of the tropical atmosphere. J. Atmos. Sci., 55, 1354-1372, https://doi.org/10.1175/1520-0469(1998)055<1354: ETGMSO $>2.0 . \mathrm{CO} ; 2$.

Yuan, J., and D. L. Hartmann, 2008: Spatial and temporal dependence of clouds and their radiative impacts on the largescale vertical velocity profile. J. Geophys. Res., 113, D19201, https://doi.org/10.1029/2007JD009722.

Yukimoto, S., and Coauthors, 2012: A new global climate model of the Meteorological Research Institute: MRI-CGCM3Model description and basic performance. J. Meteor. Soc. Japan, 90A, 23-64, https://doi.org/10.2151/jmsj.2012-A02.

Zeng, N., J. D. Neelin, and C. Chou, 2000: A quasi-equilibrium tropical circulation model-Implementation and simulation. J. Atmos. Sci., 57, 1767-1796, https://doi.org/10.1175/ 1520-0469(2000)057<1767:AQETCM>2.0.CO;2. 